\title{
A new therapeutic approach for APS?
}

Prevention of the vascular thrombosis and pregnancy morbidity associated with antiphopholipid syndrome (APS) remains an unmet clinical need, as a substantial proportion of patients with the condition are unresponsive to or experience serious adverse effects from standard anticoagulant and antiplatelet therapy. A new study published in Blood suggests that a novel approach, which uses a noncomplement-fixing monoclonal antibody against $\beta 2$-glycoprotein I ( $\beta 2 \mathrm{GPI})$, could be a useful tool in the treatment of APS.

$\beta 2$ GPI has previously been identified as a potential target antigen of pathogenic antiphospholipid antibodies (aPL) and the present work, led by Francesco Tedesco and Pier Luigi Meroni, shows that a human antibody that binds to the D1 domain of $\beta 2$ GPI with high affinity is indeed pathogenic in animal models.

Injection of the anti- $\beta 2$ GPI D1 antibody into lipopolysaccharide (LPS)-primed rats caused thrombus formation, and in pregnant mice caused fetal loss and low fetal weight, mimicking the clinical effects of aPL.

\section{4 ...the $\mathrm{CH} 2$-deleted anti- B2GPI D1 antibody could offer an innovative way to prevent aPL-induced fetal loss... 77}

However, these effects of the anti$\beta 2$ GPI D1 antibody were not observed in complement-deficient or complementdepleted animals. Furthermore, injection of a variant of the antibody engineered to lack the $\mathrm{CH} 2$ domain (which is required for $\mathrm{C} 1 \mathrm{q}$ binding and complement activation) did not affect pregnancy outcomes or coagulation in vivo. Together, these findings confirm a critical role for complement activation in the pathogenic mechanisms of aPL.

Antibody-binding assays demonstrated that the $\mathrm{CH} 2$-deleted variant bound to $\beta 2$ GPI equally as well as the parent antibody, but was unable to activate complement. On ELISA, the CH2-deleted variant was able to displace IgG from patients with APS bound to $\beta 2 \mathrm{GPI}$ on ELISA, owing to its higher affinity.

Demonstrating the potential clinical benefits of this displacement, administration of the $\mathrm{CH} 2$-deleted variant to pregnant mice and LPS-primed rats abrogated the pathogenic effects of IgG from patients with APS. The authors contend that the $\mathrm{CH} 2$-deleted anti- $\beta 2 \mathrm{GPI}$ D1 antibody could offer an innovative way to prevent aPL-induced fetal loss and thrombosis in patients refractory to standard therapy.

Sarah Onuora

Original article Agostini, C. et al. A non complement-fixing
antibody to beta-2 glycoprotein I as a novel therapy to
control abortions and thrombosis in antiphospholipid
syndrome. Blood doi:10.1182/blood-2013-11-537704

